\title{
SERAFIM DA SILVA NETO E A PROBLEMATIZAÇÃO DO CONTATO ENTRE LÍNGUAS: ALGUMAS OBSERVAÇÕES SOBRE A RELAÇÃO ENTRE OS ESTUDOS LINGUÍSTICOS E A HISTÓRIA
}

\author{
SERAFIM DA SILVA NETO AND QUESTIONING THE CONTACT BETWEEN \\ LANGUAGES: SOME OBSERVATIONS ON THE RELATION BETWEEN \\ LINGUISTICS AND HISTORY \\ Wellington Santos da Silva | Lattes | wellington.santos.silva@usp.br \\ Universidade de São Paulo | CNPq
}

\begin{abstract}
Resumo: Este artigo apresenta uma análise do tratamento que Serafim da Silva Neto (1963) dá à problemática do contato entre línguas na formação histórica do português no Brasil. Na literatura linguística contemporânea, têm sido frequentes as críticas a esse aspecto da obra do autor, pois ele minimiza o papel das línguas indígenas e africanas na configuração do português brasileiro. Deste modo, realizamos uma descrição panorâmica de como essa questão é tratada na Introdução ao Estudo da Língua Portuguesa no Brasil, mostrando que a abordagem que Silva Neto faz do problema do contato está em consonância com o modelo de análise sociocultural da língua por ele proposto. Além disso, com base em pressupostos teórico-metodológicos da Historiografia Linguística, argumentamos que as ideias do filólogo são fundamentadas nos diálogos estabelecidos entre os estudos linguísticos e a História - ou, mais especificamente, determinadas linhas historiográficas -, os quais marcaram a tradição do autor.
\end{abstract}

Palavras-chave: Contato linguístico; Historiografia Linguística; Historiografia brasileira.

\begin{abstract}
This article presents an analysis on the approach employed by Serafim da Silva Neto (1963)on the issue of the contact between languages in the historical formation of the Portuguese Language in Brazil. In the contemporary linguistic literature, criticisms to the author's work have been frequent, because he reduces the role of indigenous and African languages in the Brazilian Portuguese setting. In this way, we described an overview of how this matter is addressed in the Introdução ao Estudo da Lingua Portuguesa no Brasil, thus showing that Silva Neto's approach on the contact problem is according to the sociocultural analysis model of language proposed by him. In addition, based on the theoretical and methodological assumptions from Linguistic Historiography, we argue that the philologist's ideas are founded on the dialogues established between linguistic studies and History - or, more specifically, of certain historiographical views -, which constituted a landmark for the author's tradition.
\end{abstract}

Keywords: Linguistic contact; Linguistics historiography; Brazilian historiography. 


\section{Introdução}

Uma simples passada de olhos pela produção da Linguística brasileira contemporânea é capaz de evidenciar a grande força que têm assumido as abordagens que visam explicar a emergência de aspectos característicos do português brasileiro - doravante, $\mathrm{PB}$ - com base no contato que esta língua estabeleceu com línguas africanas e indígenas no período colonial. De modo geral, os autores que, no presente, tomam a noção de contato como princípio heurístico, o fazem ressaltando a oposição de suas ideias em relação às propostas predominantes no cenário dos estudos linguísticos brasileiros da primeira metade do século XX, posicionamento este que podemos observar nas seguintes palavras de Lucchesi (2012, p. 47):

[...] qualquer hipótese que integre o contato entre línguas na formação histórica das variedades do português brasileiro tem de enfrentar uma forte resistência subjetiva que se desdobra, tanto no plano da ideologia, quanto no plano da própria teoria linguística. Até meados do século XX, grandes filólogos brasileiros que se debruçaram sobre o tema, imbuídos da visão conservadora e preconceituosa de superioridade cultural e linguística do colonizador europeu frente às populações indígenas e africanas, procuraram minimizar qualquer interferência desses povos na formação da realidade linguística brasileira. [...]

Contrariando tal tradição, defenderemos [...] que não se pode pensar a formação histórica do português brasileiro [...] sem ter em conta centralmente a aquisição imperfeita da língua portuguesa por parte de milhões de indígenas brasileiros e africanos escravizados e a nativização dessa variedade defectiva de segunda língua entre os descendentes desse segmento, que vão constituir praticamente dois terços da população do Brasil.

Conforme nos mostra Silva (2016), dentre os principais autores que foram rotulados como fieis militantes dessa visão conservadora acerca do português falado no Brasil está Serafim Pereira da Silva Neto (1917-1960), filólogo brasileiro que foi considerado pela literatura como a principal liderança intelectual e organizacional que atuou sob essa perspectiva de análise na primeira metade do século XX (COELHO, 1998). Sendo uma de suas principais obras a seminal Introdução ao Estudo da Língua Portuguesa no Brasil - doravante, IELPB -, publicada em 1950, a visão de Silva Neto sobre a influência do contato do português com as línguas africanas e indígenas tem sido frequentemente problematizada pelos linguistas contemporâneos, que, não raro, acusam a perspectiva adotada pelo filólogo de preconceituosa. Mattos e Silva (2004, p. 32), por exemplo, embora reconheça o pioneirismo de Silva Neto na reunião de importantes fontes sócio-históricas 
para a composição do percurso histórico do PB, classifica como simplificadora a visão "lusitanófila" defendida pelo filólogo, cujo principal objetivo era sustentar a vitória da língua portuguesa no Brasil, dada a sua superioridade em relação às línguas africanas e indígenas.

Neste trabalho, acreditamos que a leitura crítica das ideias e práticas linguísticas professadas por diferentes gerações de estudiosos - como esta que tem sido feita da obra de Serafim da Silva Neto - pode ser adequadamente explicada pela noção de tradição (ALONSO, 2012), que pode ter, pelo menos, duas interpretações distintas, a saber: (i) a tradição cultural na qual está inserido um objeto cultural determinado; (ii) a tradição na qual estão inseridos os pesquisadores contemporâneos que se propõem a estudar e/ ou avaliar um objeto cultural do passado. Essa noção nos parece bastante relevante para compreender um problema que Koerner (1996, p. 49) considera bastante frequente na Linguística, que consiste no fato de linguistas contemporâneos projetarem os interesses e entendimentos atuais para teorias do passado, distorcendo os comprometimentos lá assumidos, os quais sempre têm suas razões de ser. Neste sentido, partindo dos pressupostos de que o conhecimento linguístico não emerge do vácuo, mas sim das mais diversas relações que se estabelecem num clima de opinião intelectual determinado, um dos objetivos deste artigo é, de maneira geral, dar um panorama da tradição cultural que fundamentou a emergência da IELPB e, de maneira particular, da visão que esta obra traz sobre as consequências do contato entre línguas. Como uma questão derivada desta primeira análise, nosso estudo também pretende mostrar a íntima relação que o conhecimento filológico gestado por Silva Neto estabeleceu com importantes linhas historiográficas de interpretação do Brasil, culminando numa espécie de vínculo estilístico entre as duas diferentes áreas do saber.

Deste modo, na primeira seção, explicitamos os referenciais teóricos que guiam a presente reflexão. Em seguida, damos um panorama do tratamento do contato do português com as línguas africanas e indígenas no âmbito da IELPB. Na seção seguinte, veremos como a questão brasileira foi tratada por importantes obras historiográficas da primeira metade do século XX, explicitando alguns diálogos que Serafim da Silva Neto estabeleceu com essa tradição. Neste sentido, apresentamos as relações estabelecidas entre a Filologia e a História na obra de Serafim da Silva Neto, por meio das quais o autor enfatiza a permanência portuguesa no Brasil no plano cultural e linguístico e, consequentemente, relativiza a importância efetiva dos contatos travados com as línguas indígenas e africanas. 


\section{Fundamentação teórica}

O presente estudo está inserido no campo da Historiografia Linguística, parte integrante da ciência da linguagem e definida por Swiggers (2004, p. 116) como uma disciplina dedicada ao estudo sistemático e crítico da produção e evolução das ideias e práticas linguísticas, as quais são propostas e realizadas por atores reais, sócio-historicamente situados, em interação com um contexto sociocultural e político determinado e com o passado científico e cultural. Por isso, o linguista que toma como tarefa a composição da história dos conteúdos significativos de sua área do saber, além de investigar o surgimento das ideias e práticas linguísticas, deve propor e fomentar reflexões acerca dos condicionamentos dos fatos observados. Em outras palavras, deve-se dizer que a Historiografia Linguística se configura como uma disciplina de caráter descritivo e interpretativo.

Um dos pilares da atividade historiográfica em Linguística consiste naquilo que Koerner (1996) chamou de Princípio de Contextualização, que pode ser definido como o estabelecimento do clima de opinião intelectual que subjaz ou circunda o conhecimento linguístico sob investigação. Entende-se, por este princípio, que as ideias e práticas linguísticas não nascem do vazio intelectual e ideológico, mas figuram como frutos dos aspectos que caracterizam uma determinada sociedade ou corrente sociopolítica, além, é claro, de manter relações com o conhecimento produzido em outras áreas do saber. Como exemplo do primeiro caso, podemos, novamente, mencionar o trabalho de Swiggers (2004, p. 129), que, ao tratar das metáforas científicas, cita um tratado de gramática e poética provençal produzido em meados do século XIV que, na descrição das partes da oração, utilizava termos que sugerem a influência da cultura medieval e da estrutura social do período sobre as ideias linguísticas, como a noção de 'regência', que teria sido inspirada pelo regime monárquico em voga à época.

Como se espera de qualquer atividade de caráter historiográfico, os resultados das pesquisas no âmbito da Historiografia Linguística não devem corresponder a meras fotografias ou crônicas de teorias linguísticas do passado, mas sim a abordagens descritivo-interpretativas, guiadas por fundamentos teórico-metodológicos determinados, que possibilitem elucubrações acerca dos porquês do conhecimento linguístico ter se configurado de uma forma e não de outra. Deste modo, o historiógrafo da Linguística deve tomar como diretriz uma perspectiva específica sobre o fluxo histórico das ideias e práticas científicas, perspectiva esta que sirva de fio condutor para as suas análises e propostas explanatórias. Assim, neste artigo, nossas observações acerca da constituição dos problemas científicos serão pautadas nas propostas de Fleck (2010) para a gênese dos fatos científicos. 
Ludwik Fleck (1816-1961) tem sido considerado um dos precursores da perspectiva externalista nos estudos de ciência, por entender que o conhecimento científico não corresponde a uma realidade do mundo objetivo, mas sim a uma construção resultante de relações sócio-históricas. Neste sentido, o conhecimento científico está sujeito às injunções de diversas forças socioculturais. Para Fleck, o conhecimento científico é essencialmente evolutivo, de modo que, para acessá-lo, é preciso que aqueles que se lançam ao seu estudo o façam por meio de uma epistemologia comparada:

Cada época tem concepções dominantes, resto de concepções passadas e predisposições de concepções futuras, em analogia com todas as formas sociais. Uma das tarefas mais nobres da teoria comparada do conhecimento seria a de investigar como as concepções, ideias pouco claras, circulam de um estilo de pensamento [...] para outro, como surgem pré-ideias espontâneas e como se conservam, graças a uma harmonia da ilusão, enquanto formações persistentes e rígidas. Somente por meio dessa comparação e investigação das relações chegamos a uma compreensão da nossa época. (FLECK, 2010, p. 70).

O conceito de estilo de pensamento figura como a unidade de análise básica da perspectiva teórica proposta por Fleck (2010). Em linhas gerais, este termo designa uma espécie de estrutura conceptual sócio-historicamente determinada, que conduz e direciona as percepções que os indivíduos têm do mundo numa dada época. Neste sentido, o estilo de pensamento molda as percepções nas várias esferas das práticas sociais, como na ciência, nas religiões e crenças, nas artes, nos costumes etc. Assim, quando conseguimos perceber as relações e ressonâncias existentes entre as ideias gestadas nessas diferentes esferas da vida humana, estamos diante de um caso de vínculo estilístico.

Na perspectiva de Fleck (2010), haveria diferentes estágios na evolução de um estilo de pensamento. O primeiro deles seria marcado pela falta de clareza e até mesmo pela confusão, uma vez que um estilo de pensamento do presente parece ser, necessariamente, marcado por alguns aspectos do passado, gerando, por vezes, contradições e sobreposições entre estilos divergentes. Já os estágios seguintes são caracterizados por uma maior estabilidade do estilo, que, por fim, acaba direcionando as percepções e práticas de um dado período.

A depender do contexto no qual está inserido - e, por assim dizer, que ele mesmo forma -, é possível dizer que um estilo de pensamento promove uma espécie de coerção dos pensamentos e práticas ao longo de um determinado período histórico. Assim, ao mesmo tempo em que essa estrutura conceptual proporciona e permite a visão atenta 
de alguns fatos, acaba conduzindo à negação de outros. Como exemplo, Fleck (2010) menciona a problemática da variabilidade na Bacteriologia: a existência de um estilo de pensamento rígido na área - que levava à formação de uma metodologia igualmente rígida - teria feito com que os exemplos de variabilidade fossem imperceptíveis, o que teria resultado numa espécie de "harmonia das ilusões", efeito direto da coerção promovida por um estilo de pensamento.

Os estilos de pensamento são gestados e exercitados no interior daquilo que Fleck (2010) chama de coletivos de pensamento, os quais, no caso das práticas científicas, poderiam ser identificados com os grupos científicos. Os coletivos de pensamento estáveis - ou relativamente estáveis - correspondem a grupos socialmente organizados que, por meio de suas ideias e práticas, fortalecem um determinado estilo de pensamento, fazendo-o marcante no tempo e no espaço.

No interior dos coletivos de pensamento, a formação das práticas e ideias científicas é permeada pelas interlocuções, que são entendidas por Fleck (2010) como instâncias de movimentação de pensamentos. Para se referir a esses eventos de movimentação de pensamentos - dos quais surgem os fatos científicos, por exemplo -, Fleck (2010) faz uso de dois conceitos: tráfego intracoletivo e tráfego intercoletivo. O primeiro tipo de tráfego é fundamental para o exercício do estilo de pensamento, pois é através dele que um coletivo legitima e fortalece as suas formas de pensar. Como exemplo, poderíamos fazer menção aos filólogos da geração de 1940, os quais foram identificados como um grupo bastante coeso de estudiosos da língua, dada a uniformidade das atividades a que dedicavam - edição de textos, estudos dialetais etc. - e também das concepções que eles tinham a respeito dos fatos linguísticos - como em relação à tese do conservadorismo do português falado no Brasil, por exemplo. Já o tráfego intercoletivo seria entendido como as interlocuções em grande parte das vezes, não explícitas - estabelecidas entre diferentes coletivos, como entre a Filologia e a História, por exemplo. De acordo com Fleck (2010), o tráfego intercoletivo pode ser caracterizado pela modificação sutil ou total de um estilo de pensamento, pois, uma vez que ocorre por meio da relação entre diferentes domínios do saber, abre-se espaço para a descoberta de novos fatos científicos. Na perspectiva de Fleck (2010), um dos elementos mais sensíveis ao fenômeno de tráfego intercoletivo é a palavra ou, por assim dizer, os termos científicos. Segundo o autor, uma vez que as palavras são marcadas por um estilo de pensamento determinado, quando passam pelo tráfego, elas têm o seu significado parcial ou totalmente modificado. 
Levando todos esses aspectos em consideração, propomos neste trabalho que a relação entre Linguística e História pode ser exemplificada com a obra de Silva Neto (1963), sobretudo pela abordagem que o autor faz do problema do contato do português com as línguas africanas e indígenas. Conforme procuramos mostrar adiante, houve um vínculo estilístico entre a Filologia e a Historiografia brasileira da primeira metade do século XX, configurado na forma de um tráfego intercoletivo de pensamento.

\section{Silva Neto (1963) e a problematização das teses negrófilas e indiófilas ${ }^{1}$}

Obra publicada por um dos maiores expoentes dos estudos filológicos brasileiros do século XX (COELHO, 1998; LOBO, 1994; SILVA, 2016), sabe-se que a IELPB emerge num contexto de discussões bastante candentes sobre a existência ou não de uma língua brasileira. De acordo com Elia (1961), os estudiosos que defendiam a questão argumentavam com base na influência que as línguas indígenas e africanas teriam exercido sobre o português, devido à situação sociolinguística de contato. Assim, ao contrário do que era tradicionalmente assumido, para autores como Renato Mendonça ${ }^{2}$ (1935) e Jacques Raimundo ${ }^{3}$ (1933), a contribuição das referidas línguas no português não teria ficado circunscrita ao léxico, mas também poderia ser encontrada nos elementos da gramática. Na IELPB, Silva Neto, que era contrário a tais hipóteses, parece desejar por uma espécie de ponto final nessa discussão, esclarecendo alguns pontos que, em sua concepção, não teriam sido adequadamente analisados por seus contemporâneos ou predecessores, sobretudo aqueles relativos ao problema do contato.

Tomando o fenômeno de ascensão social do mestiço como um dos principais fios condutores da história externa do português no Brasil, podemos dizer que Silva Neto (1963) constrói uma reflexão de feição sociolinguística ${ }^{4}$, calcada, fundamentalmente, na noção de prestígio social, como podemos ver no seguinte trecho da obra, no qual o filólogo procura apresentar o modo de estruturação da sociedade colonial:

Ora, nos dois primeiros séculos do Brasil colonial "os elementos oficiais e os colonos formariam uma casta superior, sendo que os nascidos em Portugal se considerariam acima dos que houvessem por berço a colônia.

\footnotetext{
${ }^{1}$ Os termos 'negrófilos' e 'indiófilos' são utilizados por Serafim da Silva Neto, para se referir aos argumentos a favor da influência das línguas africanas e indígenas sobre o português.

2 Biodatas: (1912-1990)

${ }^{3}$ Biodatas: (? - 1905)

${ }^{4}$ Tal qual argumenta Silva (2016), utilizamos o termo feição sociolinguística para fazermos referência a trabalhos que, embora não estivessem vinculados à atual disciplina conhecida como Sociolinguística - cujo início remete aos anos 1960 -, foram estruturados de acordo com uma perspectiva sociocultural para o estudo da linguagem.
} 
Estes últimos vinham em segunda linha, muito pouco considerados pelos reinóis vindos da Europa, e eles aceitavam essa diminuição de conceito e de classe", logo abaixo desse grupo estavam "os mestiços de índios, que não admitiam fossem colocados no mesmo nível dos mulatos e dos demais cruzados de brancos e negros; alegavam, antes, a ascendência paterna, a proteção que, oficialmente, Portugal lhes dispensava, ao promover os casamentos mistos entre europeus e autóctones" - em seguida vinham os mulatos e, depois dêles "vinha uma indescritível mistura de inomináveis cruzes: mulato-índio; índio negro" - abaixo estavam os escravos vermelhos, e, ainda mais baixo a massa africana e sua linhagem racial. (SILVA NETO, 1963, p. 103-104).

Ancorando-se na proposta do sociólogo americano Thorstein Bunde Veblen (18571929), Silva Neto assume que a sociedade colonial era organizada em forma piramidal, de modo que os indivíduos menos privilegiados ocupavam a base da estrutura e os mais prestigiados, o seu topo, conforme pudemos constatar da leitura do trecho há pouco citado. Na perspectiva do filólogo, galgar posições ao longo da pirâmide seria, por assim dizer, o objetivo de qualquer indivíduo situado naquela formação social. Deste modo, Silva Neto 1963 também lança mão do conceito de leis da imitação, proposto pelo sociólogo francês Jean-Gabriel De Tarde (1843-1904), segundo o qual a imitação do socialmente superior pelo socialmente inferior consistiria no modus operandi da sociedade. Assim, existiriam as chamadas tendências positivas, segundo as quais seria favorecida a imitação dos caracteres dos estratos sociais superiores, e as tendências negativas, segundo as quais as características dos estratos inferiores seriam evitadas.

Na sociedade colonial - na forma em que é descrita por Serafim da Silva Neto -, os brancos portugueses ocupavam o topo da pirâmide social e, por esta razão, configuravam-se como os principais veículos de tendências positivas, ou seja, eram imitados por aqueles que ocupavam espaços mais baixos na pirâmide. No extremo oposto, estavam os negros, razão pela qual veiculavam tendências negativas, isto é, suas características eram evitadas pelos indivíduos socialmente mais privilegiados. Tal equação que, com base nos conceitos sociológicos, foi formulada por Silva Neto (1963), traz algumas consequências interpretativas para o problema investigado na obra, qual seja a história da língua portuguesa no Brasil. Uma delas é a ideia de ascensão social do mestiço: ao propor a periodização da história linguística do Brasil, a qual culmina com a tese da vitória da língua portuguesa, Silva Neto (1963) toma como fio condutor a ascensão social do mestiço, fenômeno que, no plano linguístico, também se traduzia no processo branqueamento ou, nas palavras do filólogo, branquização linguística:

A ascensão social do mestiço acarretava polimento e planificação na 
linguagem, uma vez que esse é um importantíssimo sinal-marca de classe social. O negro de Frágua de Amores, de Gil Vicente, desesperavase porque inutilmente lhe branqueara a pele: na linguagem se traía a cor. (SILVA NETO, 1963, p. 106).

A natureza da concepção sociocultural defendida por Silva Neto (1963) também teve importantes impactos na proposta que o filólogo fez para a periodização da história linguística do Brasil, a qual, a propósito, também foi guiada pela noção de ascensão social do mestiço. Silva Neto (1963) propõe que a história linguística do Brasil seja dividida em três diferentes períodos, a saber: (I) de 1532 a 1654; (II) de 1654 a 1808; e (III) de 1808 em diante. Como bem explica o filólogo, a periodização proposta não se baseia nos dados de mudança das estruturas linguísticas propriamente ditas, mas sim na história externa da língua. Assim, sua intenção parece ser mostrar a maneira como o português, de modo paulatino, foi se tornando uma língua vitoriosa, suplantando as variedades linguísticas de menor prestígio.

Na perspectiva de Silva Neto (1963), na sociedade colonial, cada raça ou etnia representava uma classe social distinta, a qual, por conseguinte, também apresentava uma linguagem diferente que, no plano da arena social, reagia sobre as outras. Além disso, ao longo da periodização proposta pelo filólogo, vão ocorrendo mudanças na distribuição demográfica de cada uma das etnias, desde o desaparecimento dos índios - que tinham presença marcante no primeiro período - até a grande migração de portugueses para o Brasil, no século XIX, na companhia da família real. Este fato teria definido o caráter português do Brasil - ou, melhor dizendo, a vitória dessa língua -, daí a ausência de fechamento do terceiro período na proposta de Silva Neto.

Outro elemento bastante importante no modelo de feição sociolinguística proposto por Silva Neto (1963), e que se coaduna com os conceitos sociológicos movimentados por ele, é a forte oposição entre a cidade e o campo. Assim, na IELPB, as variedades urbanas seriam dotadas de características distintas dos chamados falares regionais. Na perspectiva do filólogo, nas cidades, as forças de planificação linguística eram mais atuantes, havia oportunidades de escolarização e também a maior presença de pessoas brancas, isto é, com maior prestígio social. A zona rural, por seu turno, além de não contar com os instrumentos de planificação linguística - como a escola, por exemplo -, ainda tinha uma maioria demográfica de negros e índios, fato este que abria espaço para a atuação das leis de imitação: ${ }^{5}$

\footnotetext{
${ }_{5}^{5}$ Neste ponto, seria possível fazer um questionamento ao modelo teórico proposto por Silva Neto (1963), uma vez que seria difícil aos falantes rurais imitarem os usos linguísticos urbanos, com os quais eles, possivelmente, tinham pouco contato.
} 
As cidades figuram como centros de áreas circulares ou semicirculares de onde se irradiam para a periferia fluxos de influência do falar urbano. É uma ação lenta, mas progressiva e eficiente.

Assim se estabelece uma linha de gradações planificadoras, que se vai acentuando à proporção que da periferia se caminha para o centro [...] (SILVA NETO, 1963, p. 88).

É no interior dessa perspectiva sociocultural que também irá se configurar o tratamento que Silva Neto (1963) dará à problemática do contato do português com as línguas indígenas e africanas, como podemos notar no seguinte trecho, retirado das páginas iniciais do capítulo que o filólogo dedica especialmente à discussão dessa temática:

Com respeito à situação do Brasil-Colônia é preciso, porém, não exagerar. É certo que o meio social era perturbado por elementos extra-europeus, índios e negros. Mas deve ter-se na devida conta que sempre o branco se estremou socialmente, como classe superior. E que um dos característicos de classe social é, precisamente, a linguagem. Ela até classifica socialmente os indivíduos. (SILVA NETO, 1963, p. 102-103).

Como a passagem acima citada mostra, pelo fato de tomar como modelo a estratificação da sociedade colonial, caracterizada por relações totalmente verticalizadas entre as classes, Silva Neto nega que os negros e indígenas tenham influenciado substancialmente o desenvolvimento do português no Brasil. Munindo-se dos conceitos de tendências positivas e tendências negativas, o filólogo parte do pressuposto de que, por constituírem a base da pirâmide social, os negros, índios e mestiços não gozariam de prestígio diante de seus contemporâneos e, por tal razão, veiculariam tendências negativas nos socialmente mais privilegiados, isto é, inibiriam a imitação de seus traços linguísticos, mesmo que tenham deixado alguns de seus traços em outras áreas da cultura:

Do branco prevaleceu a religião, os hábitos, a língua. É certo que no tocante à etnografia algo nos ficou do negro e do índio: mas a língua, dentre todas as instituições sociais é a que mais fortemente se impõe aos indivíduos. E por isso mesmo ela não sofreu influências decisivas, senão apenas incorporações ao vocabulário e à fraseologia bem como um ou outro fato restrito a falares regionais. (SILVA NETO, 1963, p. 106).

Ora, não obstante Silva Neto (1963) apresenta um posicionamento claro na IELPB quanto à tese da vitória da língua portuguesa no Brasil e, por consequência, quanto à fraqueza da influência que as línguas africanas e indígenas exerceram sobre a língua ven- 
cedora, o filólogo também aventa a hipótese da existência de um crioulo ou semicrioulo ${ }^{6}$ português no período colonial. Voltando-nos para a periodização proposta por ele, mais especificamente para o segundo recorte temporal - de 1654 a 1808 -, vemos o autor chamar a atenção para o decréscimo da população indígena - e, consequentemente, para o enfraquecimento do uso da língua geral - e, em oposição a isso, para o crescimento do número de brancos e negros na Colônia. Além dessas modificações da composição demográfica do país, o filólogo nos informa que, também nesse período, teria ocorrido a expansão territorial para o interior, processo este que contou com a massiva participação dos índios remanescentes, dos negros e dos mestiços. $\mathrm{O}$ contato entre esses indivíduos de etnias diversas - e, por conseguinte, falantes de línguas distintas - teria dado origem a uma língua crioula ou, pelo menos, a uma variedade semicrioula. Segundo Silva Neto (1963), a existência de falares crioulizados dependia diretamente da composição demográfica da população: quanto maior a presença de negros, índios e mestiços numa comunidade, maior também seria a tendência de existir ali um crioulo.

Entretanto, na perspectiva de Silva Neto (1963), a existência de falares crioulos teria sido uma realidade apenas dos primeiros tempos da colonização, uma vez que, paulatinamente, tais variedades linguísticas eram aperfeiçoadas por meio do contato com os brancos e com a escolarização. Deste modo, emerge na IELPB o conceito de semicrioulo, termo utilizado para designar uma variedade que, mesmo trazendo as marcas do uso linguístico dos indivíduos menos privilegiados da sociedade - o que Silva Neto (1963, p. 107) chama de cicatrizes características dos falares crioulos -, passara por um processo de mudança linguística, aproximando-se cada vez mais do português: ${ }^{7}$

Nos crioulos há vários graus de aprendizagem, pois, segundo as circunstâncias, o primitivo falar xacoco se mantém ou é aos poucos renovado pelo sangue novo da língua europeia. De geração em geração, à custa sobretudo da escola, se vai aperfeiçoando e enriquecendo a primitiva fala de emergência. [...]

Daí admitir-se a existência do semicrioulo, ou seja, um estágio aperfeiçoado da primitiva aprendizagem. (SILVA NETO, 1963, p. 108).

Ora, o próprio uso do termo semicrioulo e tudo o que ele significa nos ajuda a ver que, não obstante fazer menção às variedades linguísticas que surgiram como frutos explícitos das situações de contato entre línguas, Silva Neto (1963) ainda está atuando no

\footnotetext{
${ }^{6}$ Lucchesi (2012, p. 52) afirma que Serafim da Silva Neto foi visionário ao formular o conceito de semicrioulo para caracterizar os efeitos do contato entre línguas na formação do $\mathrm{PB}$, mas que, ainda assim, tomou o conceito de deriva como diretriz analítica.

7 Autores como Tarallo (1993) chamam esse processo de descrioulização.
} 
interior da perspectiva sociocultural aqui descrita, ou seja, aquela que atribuía uma força considerável à civilização europeia e corroborava a tese da vitória da língua portuguesa no Brasil. Tais aspectos ficam ainda mais claros quando observamos o uso que o filólogo faz do conceito de deriva e também da tese do português falado no Brasil como uma língua transplantada.

Conforme já temos visto, Silva Neto (1963) não nega que tenha ocorrido um franco processo de contato massivo no Brasil Colonial. Aliás, a própria formulação do conceito de semicrioulo evidencia que o autor reputava como necessário o tratamento da questão. Além disso, sua obra tem sido considerada uma espécie de repositório de fontes para a composição de uma história linguística que contemple a participação de negros e indígenas na formação do PB, dada a documentação reunida pelo autor, como excertos que simulam as falas de escravos, por exemplo (Cf. MATTOS; SILVA, 2004; SILVA, 2016). Entretanto, o ponto interessante na IELPB é que, mesmo trazendo uma documentação que, a depender do prisma analítico, poderia endossar perspectivas que defendessem impactos radicais decorrentes da situação de contato, Silva Neto procura relativizar o papel que os aloglotas - isto é, os negros e indígenas que adquiriam o português como uma língua de emergência, no Brasil Colonial - tiveram na história do $\mathrm{PB}$, definindo-os como protagonistas apenas da deflagração da deriva da língua: os aloglotas não trariam elementos de suas línguas maternas para o português - como defendiam autores como Renato Mendonça -, mas apressariam processos de mudança já latentes naquela língua.

Na IELPB, o conceito sapiriano de deriva é utilizado com frequência justamente no capítulo dedicado ao estudo do contato linguístico no Brasil Colonial. Fazendo uso desse conceito, Silva Neto (1963) se propõe a problematizar o que ele chama de teses negrófilas e indiófilas, segundo as quais seria possível falar na existência de uma língua genuinamente brasileira, totalmente diferente do português falado em Portugal, porque as línguas africanas e indígenas teriam exercido uma influência radical na língua falada no Brasil. Para Silva Neto (1963), muitos dos aspectos do PB que alguns estudiosos atribuíam ao contato com as línguas indígenas e africanas seriam, de fato, tendências já presentes na língua desde Portugal, as quais, devido às forças sociais atuantes na sociedade colonial - como a presença massiva de aloglotas, por exemplo -, teriam sido aqui deflagradas e, posteriormente, perenizadas em alguns dos falares regionais. Vejamos, a esse respeito, a análise que o filólogo propõe para alguns fenômenos fonológicos:

Tais pronúncias [...] pertencem àquela categoria de tendências já contidas na deriva da língua que logo irrompem quando o meio social 
é turvo e incerto pela convivência de populações de origens diversas e a consequente falta de uma rígida norma linguística.

São, portanto, pronúncias devidas a relaxamento de articulação, imputáveis ao desleixo de aloglotas os quais, de modo geral precipitam a deriva da língua. Não são, é preciso frisar, fatos decorrentes de fenômenos de interferência linguística: não se pode falar aqui em influência de línguas americanas ou africanas. (SILVA NETO, 1963, p. 196).

No exemplo acima citado, por meio do uso do conceito de deriva, Silva Neto (1963) quer dizer que as mudanças fonológicas atestadas fariam parte de tendências já prefiguradas na variedade europeia do português e, por isso, a qualquer momento iriam ocorrer - mesmo na variedade falada em Portugal -, devido à ação de forças internas à língua, isto é, independentemente da situação de contato.

De acordo com Silva Neto (1963, p. 101), os estudiosos que, a qualquer preço, propunham teses indiófilas e negrófilas para explicar os traços característicos do português falado no Brasil incorriam em sérios erros teórico-metodológicos. Primeiramente, segundo o filólogo, muitos deles desconheciam as línguas africanas e indígenas em nome das quais advogavam a força do contato. Além disso, faltava-lhes um conhecimento detalhado do que ele chama de cultura linguística e românica. Como alternativa, Silva Neto propunha que o processo de análise deveria ocorrer da seguinte forma:

[...] investigar profundamente o fenômeno linguístico em causa, para saber se êle se verificou a dentro da língua portuguêsa ou mesmo se nela poderia ter-se desenvolvido, independentemente de qualquer contato: investigar, outrossim, o mesmo fato na vasta área por onde se espraiou o português, para ver se pode tratar-se de uma evolução devida a aloglotas, que em geral, precipitam a deriva imanente à língua. (SILVA NETO, 1963, p. 119).

Conforme a análise apresentada em Silva (2016), acreditamos que essas propostas de Silva Neto (1963) para a abordagem do problema do contato entre línguas estão fortemente ancoradas em outro pressuposto defendido na IELPB, qual seja a hipótese do português falado no Brasil como uma língua transplantada, isto é, uma língua transportada para outro espaço geográfico, em decorrência do processo de colonização. De acordo com Silva Neto (1963), a variedade brasileira do português apresentaria, no que diz respeito aos fenômenos linguísticos a que ela estaria suscetível, muitas semelhanças com outras variedades linguísticas surgidas em contextos de colonização, a saber: conservadorismo, koinetização e apressamento dos prazos evolutivos - ou, em outras pala- 
vras, apressamento da deriva. Centrando-nos na última destas três propriedades, vemos que, na perspectiva do filólogo, mudanças linguísticas que, em condições normais, levariam séculos para serem concretizadas em uma língua - por fazerem parte de sua deriva -, ocorreriam de forma abrupta nas línguas transplantadas, dadas as especificidades dos condicionamentos socioculturais. Por meio da argumentação de Silva Neto, vemos que embora muitos traços linguísticos característicos das línguas transplantadas também se façam presentes nas línguas crioulas - exemplos mais emblemáticos do impacto do contato entre línguas -, existem diferenças nos caminhos que os fenômenos de mudança tomam naquelas primeiras línguas:

\footnotetext{
Postas assim as premissas, vemos claramente que certas mudanças verificadas na linguagem rural ou dialetal do Brasil se explicam, não pela interferência de qualquer substrato ou adstrato, mas por uma rápida evolução, apressada por aloglotas. O papel destes consistiu, aqui, como alhures, em realizar de imediato o que, em condições normais, levaria talvez séculos para completar-se.

$\mathrm{Na}$ fonética há dois exemplos bastante expressivos. Um é o caso da iotização de lhê [...] que igualmente se dá nos crioulos de Cabo Verde, da Guiné, nas Ilhas do Príncipe e de S. Tomé. Não importa que fenômeno igual ou semelhante se tivesse dado no transcurso da evolução da língua francesa ou de qualquer outra... No nosso caso particular e histórico, observamos que os aloglotas (mouros, índios e negros) se mostraram sempre incapazes de pronunciar 1 . (SILVA NETO, 1963, p. 130).
}

No trecho acima, vemos que Silva Neto (1963) procura acentuar a especificidade da ocorrência das mudanças fonéticas tratadas no português falado no Brasil, uma língua transplantada: as mudanças não se deram nem por influência de substrato ou adstrato, como fora o caso das variedades crioulas mencionadas, gestadas em condições de contato massivo, e nem no correr dos séculos, como uma mudança lenta e gradual, prefigurada na deriva. Em consonância com a segunda opção, as mudanças no português falado no Brasil estavam presentes em sua deriva, mas teriam sido apressadas pela pronúncia dos aloglotas, fato bastante característico das línguas transplantadas.

Em linhas gerais, pode-se dizer que, por detrás do conceito de língua transplanta$d a$, está a ideia de que o português falado no Brasil é, por assim dizer, uma continuidade do português falado em Portugal, a outra ponta do domínio linguístico. Aliás, a hipótese do conservadorismo parece deixar essa ideia um pouco mais clara, pois por meio dela se argumenta que o português falado no Brasil teria conservado propriedades gramaticais e fonéticas do português do século XVI, ao passo que a variedade lisboeta teria passado por 
posteriores processos de mudança. Vejamos, a esse respeito, o tratamento que Silva Neto (1963) dá à pronúncia das vogais pretônicas no dialeto nordestino, endossando a análise de Joaquim da Silveira:

[...] Acentuemos também, contudo, a opinião do Dr. Joaquim da Silveira, expressa nestas palavras: "Êsse característico relevo que na pronúncia de lá, se dá em regra às vogais pretônicas [aliás só na pronúncia do Nordeste, repita-se] e que ao primeiro contato tanto nos impressiona, constitui uma barreira à respectiva degeneração e deve representar, no fundo não uma modulação emergente da glote indígena, como já se tem dito, mas um eco mais nítido e bem conservado do nosso antigo vocalismo" (in Brasilia, II). (SILVA NETO, 1963, p. 189).

No trecho acima, vemos que Silva Neto endossa a análise de Joaquim da Silveira sobre a pronúncia das vogais pretônicas no dialeto nordestino, a qual, em linhas gerais, nega que o fenômeno linguístico em questão tenha sido causado pelo contato com as línguas indígenas, mas seria uma espécie de ampliação de um processo já ocorrido em Portugal, em que todas as vogais pretônicas originadas de antigas crases do português arcaico seriam pronunciadas como vogais abertas. Fenômenos como esse fariam do português falado no Brasil uma língua conservadora, uma das principais marcas das línguas transplantadas.

Ora, Silva (2016) argumenta que o uso do conceito de língua transplantada por parte de Silva Neto (1963) - e dos demais conceitos a ele relacionados - pode ser entendido como uma estratégia de adaptação. De acordo com Swiggers (1988) - que estudou as primeiras gramáticas dos vernáculos europeus, a fim de mostrar como elas foram construídas sob a forte influência da gramaticografia latina -, nem sempre a análise de estruturas linguísticas novas - isto é, no plano documental - leva a uma descrição original dos fatos linguísticos. Por vezes, o peso de uma certa tradição de análise pode fazer com que os fenômenos linguísticos fiquem submissos a uma determinada teoria, levando àquilo que Swiggers (1988) chama de estratégias de adaptação. Estudando as primeiras gramáticas do galo-românico, por exemplo, o historiógrafo percebeu a estratégia de transferência direta, por meio da qual as estruturas linguísticas do galo-românico - distintas das estruturas latinas - eram nomeadas pelos mesmos termos das partes do discurso latinas, uma vez que os gramáticos entendiam que as novas formas - ainda desconhecidas - pudessem ser designadas e explicadas pelas mesmas classes. Com base nesse exemplo, Silva (2016, p. 137) propõe que, não obstante lide com fenômenos linguísticos característicos do português falado no Brasil, o desejo de Silva Neto (1963) parece ser vincular a IELPB 
à tradição filológica portuguesa ${ }^{8}$ e, por tal razão, acaba utilizando estratégias de adaptação. Ao utilizar o conceito de deriva, por exemplo, para negar a influência das línguas africanas e indígenas sobre o português, o filólogo parece utilizar uma estratégia de transferência direta: os processos de mudança ocorridos na variedade brasileira do português representam fenômenos já ocorridos ou prefigurados na língua de Portugal - ou até mesmo em outras línguas românicas -, tornando possível a sua categorização como uma língua transplantada, uma continuidade do português, só que no Brasil.

Nesta seção, procuramos dar um quadro geral do modelo de feição sociolinguística movimentado por Silva Neto na IELPB e suas consequências para o tratamento do contato entre línguas. Conforme pudemos ver, levando em consideração a maneira como a sociedade colonial era estruturada, na perspectiva de Silva Neto (1963) os negros e indígenas não poderiam exercer influências decisivas sobre o português, língua que funcionava como símbolo de uma civilização entendida como superior. Por essa razão, o autor parece formular uma análise de mudança que corrobore a sua tese da vitória da língua portuguesa no Brasil, qual seja a hipótese da língua transplantada. Através das propriedades que decorrem desse conceito - como o apressamento da deriva e o conservadorismo, por exemplo -, o autor demarca a continuidade do português no Brasil e também consegue negar as teses indiófilas e negrófilas.

Conforme já mencionamos, esse posicionamento de Silva Neto é frequentemente criticado pela literatura contemporânea, ou, melhor dizendo, pela tradição que subsume esses pesquisadores. Entretanto, como uma das tarefas da Historiografia Linguística é propor os condicionamentos que levaram um determinado conhecimento linguístico a se estruturar de uma forma e não de outra, na próxima seção, procuraremos mostrar como alguns importantes trabalhos da Historiografia de intepretação do Brasil, produzidos na primeira metade do século XX, podem ter impactado a obra de Serafim da Silva Neto, traduzindo-se num vínculo estilístico.

\section{Algumas observações sobre o vínculo estilístico: Silva Neto (1963) e a historiografia brasileira}

Tomando como diretriz o princípio de contextualização (KOERNER, 1996), procuramos mostrar, nesta seção, o contexto de emergência da IELPB e a maneira como esta obra dialogou com uma certa linha historiográfica de interpretação do Brasil, configurando-se, assim, um tráfego intercoletivo de pensamento.

\footnotetext{
${ }^{8}$ Silva (2016) traz uma argumentação mais detalhada para esta argumentação, recorrendo inclusive a outros trabalhos de Serafim da Silva Neto.
} 
Num trabalho em que se propõe a analisar as várias perspectivas que direcionaram a interpretação historiográfica da Independência do Brasil, Costa (2006) afirma que houve, em relação a essa temática, um conjunto de trabalhos caracterizados por um léxico de continuidade, isto é, que pintaram o processo de Independência como um dos resultados do sucesso da empresa colonialista portuguesa, cujo ápice teria sido a emancipação da porção americana do império. Segundo a autora, um dos melhores exemplos desse tipo de visão poderia ser verificado no trabalho do historiador Francisco Adolfo de Varnhagen (1816-1878), autor da História Geral do Brasil (1854), obra patrocinada pela Coroa e considerada como fundadora da historiografia nacional. De acordo com Costa (2006), Varnhagen ficou conhecido por sua interpretação lusófila da relação entre Brasil e Portugal, que enfatizava os aspectos de continuidade portuguesa na passagem do período colonial para o Brasil Independente e atribuía características positivas ao processo. Para a autora, os principais eixos de interpretação do Brasil na obra de Varnhagen eram: a primazia da cultura e da raça europeia sobre as suas correspondentes autóctones e africanas e a superioridade da Monarquia sobre a República.

Varnhagen é um dos primeiros historiadores citados na IELPB. Aliás, é uma passagem deste historiador que Silva Neto utiliza para encorajar o estudo das variedades faladas do português brasileiro, dada a sua diferença de acento em relação a Portugal. Levando em consideração as observações de Costa (2006) sobre a maneira como os africanos e indígenas eram vistos numa historiografia como a defendida por Varnhagen, que exaltava a superioridade branca, argumentamos que traços semelhantes podem ser encontrados na abordagem de Serafim da Silva Neto:

Há ainda referências, no Brasil-Colônia, ao uso de línguas africanas nas aglomerações negras das cidades.

Cedo, porém, saíram do uso, com a expansão, cada vez maior do português. O idioma dos descobridores, com seu alto prestígio de língua escrita e rica literatura, foi absorvendo os focos não românicos: os episódicos falares africanos e a pertinaz língua geral, que só muito lentamente foi cedendo terreno (SILVA NETO, 1963, p. 86).

Como podemos ver acima, tal qual ocorre na obra de Varnhagen, Silva Neto (1963) exalta a proeminência da cultura branca e europeia sobre os indígenas e africanos. Contudo, embora afirmações como as dele sejam consideradas preconceituosas pelos linguistas do presente, nosso intuito é mostrar que, à época, havia um clima de opinião intelectual que favorecia interpretações dessa natureza. 
Conforme mencionamos na seção anterior, Silva Neto (1963) constrói a sua análise linguística com base no pressuposto da existência de características opostas na composição demográfica e social das zonas urbanas e das zonas rurais, diferenças estas que, por conseguinte, se traduziriam também em diferenças de caráter linguístico. Para o filólogo, nas cidades, haveria uma manutenção do padrão linguístico português devido à maior presença de pessoas brancas, enquanto os espaços rurais, habitados por uma grande massa de negros e indígenas, apresentariam as já citadas variedades linguísticas crioulizadas. Tais observações de Silva Neto são guiadas por informações historiográficas, pois, como exemplo, podemos citar o seguinte trecho de Caio Prado Jr., transcrito pelo filólogo no quinto capítulo da IELPB:

É assim que êle se concentra nos grandes núcleos agrícolas do litoral: no Maranhão, no Extremo Nordeste, no Recôncavo baiano, no Rio de Janeiro. Assim também nos centros mineradores do interior: Minas Gerais, Goiás, Mato Grosso. Em todos êstes pontos, o negro e seus derivados francamente preponderam. Mas entre si, aquelas regiões se distinguem por certos caracteres próprios. Nas de propriedade mais antiga [...] a difusão do sangue negro se fez em maior escala, e daí uma tendência para a eliminação do branco puro e mesmo do quase puro. Mas embora só propriamente nos maiores centros urbanos, age uma tendência contrária a esta: é o afluxo, mais numeroso do que em outros lugares, de imigrantes brancos [...]. (PRADO JR. apud SILVA NETO, 1963, p. 144).

Outro autor que é lembrado por Costa (2006, p. 69) por enfatizar a continuidade portuguesa decorrente do processo de Independência é Francisco José de Oliveira Viana (1883-1951). Há cinco menções à obra de Oliveira Viana na IELPB, as quais fundamentam e fortalecem as análises linguísticas propostas por Silva Neto, como no seguinte trecho, em que o autor novamente destaca a superioridade dos espaços urbanos frente à zona rural:

Também queremos trazer à colação importante fato, que não passou despercebido aos olhos argutos de Oliveira Viana. É que nas cidades, pelo menos a partir do século XVII, se concentravam os elementos brancos da colônia: elas "funcionavam como poderosos centros de seleção e concentração dos elementos brancos superiores". (SILVA NETO, 1963, p. 88).

O referido trecho compõe as observações de Silva Neto a respeito da periodização da história linguística do Brasil, mais especificamente sobre o terceiro período, durante o 
qual, na concepção do filólogo, teria ocorrido a demarcação da identidade portuguesa no território brasileiro, nos vários elementos da cultura. Assim, importa ao autor a reunião de argumentos que acentuem o fortalecimento da cultura urbana e branca, e, em contrapartida, mostrem a eliminação e/ou marginalização dos elementos não compatíveis com ela. É neste sentido que entram as observações de Oliveira Viana, a fim de ajudar o filólogo a comprovar a sua tese no âmbito linguístico, a saber: a vitória da língua portuguesa.

De acordo com Bastos (2006), um dos temas mais estudados pelos intelectuais brasileiros da década de 1920 dizia respeito à busca de uma identidade nacional, problema este que, necessariamente, passava pela reinterpretação dos processos de colonização e Independência. Neste sentido, Bastos (2006, p. 68) afirma que em alguns estudos era possível notar uma espécie de revalorização da influência lusitana na formação do Brasil, sendo um dos representantes desta corrente o sociólogo Gilberto Freyre (1900-1987). A esse respeito, vemos em Vellinho (1962, p. 524) que, já no período precedente à produção de Freyre, muitos estudos de interpretação do Brasil partiam do pressuposto de que a história brasileira se tratava de um prolongamento da história do Velho Mundo. Em Freyre, entretanto, o Brasil seria entendido como uma nação mestiça, na qual a herança europeia, no plano racial e cultural, teria se juntado às formas de vida extra-europeias.

Ora, Gilberto Freyre é amplamente citado na IELPB. Como um exemplo, podemos mencionar a alusão feita à obra Sobrados e Mucambos, utilizada por Silva Neto para salientar o fortalecimento do uso do português no Brasil Colonial, mesmo diante do uso da língua geral, visto que Freyre trazia o registro de que, em 1562, um índio adolescente pregara em português a Paixão de Cristo. Além disso, o filólogo afirma que na Sociologia de Freyre poderiam ser encontrados argumentos para se defender a ideia de que, nos processos de ascensão social, os indivíduos sentiam a necessidade da branquização linguística.

Tendo em vista as referências textuais aqui apresentadas - e outras que, mesmo constantes da IELPB, fogem do escopo deste trabalho -, argumentamos que a obra de Silva Neto (1963) estabeleceu um franco diálogo com uma determinada linha historiográfica de interpretação do Brasil, isto é, com os trabalhos que salientavam a continuidade e sobreposição portuguesa na cultura brasileira, mesmo diante da independência política, o que mostra que a IELPB estava, por assim dizer, afinada com as interpretações circulantes nesse clima de opinião intelectual. Assim, tendo como base as propostas de Fleck (2010), afirmamos que a IELPB constitui-se num exemplo de concretização de um tráfego intercoletivo de pensamento, por meio do qual concepções carreadas por estudos de interpretação histórica e social do Brasil, sobretudo aqueles produzidos nas décadas de 
1920 e 1930 - década na qual a IELPB começou a ser escrita -, passaram para o terreno dos estudos linguísticos. Neste sentido, sugerimos que, nesse período, parece ter ocorrido um vínculo estilístico entre os estudos que, em diferentes áreas, se propuseram a interpretar o fenômeno brasileiro. Deste modo, as diferentes áreas ou coletivos de pensamento convergiram num viés interpretativo, guiados pelo mesmo estilo de pensamento, segundo o qual haveria uma continuidade entre Portugal e Brasil.

Partindo do pressuposto de que um estilo de pensamento promove, numa determinada época, a coerção dos pensamentos e práticas, bem como conduz à negação de fatos que não convirjam com a visão por ele propalada, argumentamos, também, que o vínculo estilístico descrito pode ser considerado como uma das razões que fizeram com que a tradição representada pela IELPB ${ }^{9}$ problematizasse os impactos do contato entre línguas na formação histórica do português no Brasil, fato que, numa tradição contemporânea, tem sido fortemente enfatizado.

\section{Conclusão}

Este trabalho teve como objetivo descrever alguns aspectos da problematização que Silva Neto (1963) faz do impacto do contato entre línguas na formação histórica do português no Brasil. Deste modo, munidos de alguns conceitos teórico-metodológicos da Historiografia Linguística - e, no que diz respeito à proposta de Fleck (2010), da Historiografia das Ciências de modo geral -, verificamos que as ideias propaladas pelo filólogo, situado em uma tradição particular, atualmente vistas como simplistas e preconceituosas, encontram sua sustentação em um íntimo diálogo entre os estudos linguísticos e uma determinada linha historiográfica de interpretação do Brasil, diálogo este que analisamos com base nos conceitos de vínculo estilístico e tráfego intercoletivo de pensamento.

Como a análise procurou mostrar, o estudo da emergência e do desenvolvimento do conhecimento linguístico deve, necessariamente, estar calcado no exame atento do contexto que possibilita que ele tenha determinadas características, e não outras. $\mathrm{Na}$ tradição na qual estava inserido Serafim da Silva Neto, em que os grandes expoentes da classe intelectual acentuavam as continuidades das marcas portuguesas na estruturação da cultura brasileira, a consonância em relação a essas ideias no plano dos estudos linguístico-filológicos já era, por assim dizer, esperada. ${ }^{10}$ Neste sentido, as próprias noções

\footnotetext{
${ }^{9}$ Afirmamos que a tradição foi representada pela IELPB de Silva Neto por ser ele o grande expoente dos estudos filológicos da primeira metade do século XX. Contudo, outros autores defenderam ideias semelhantes no mesmo contexto, como Gladstone Chaves de Melo (1917-2001) e Sílvio Edimundo Elia (19131998).

${ }^{10}$ Uma importante questão a ser respondida, em uma futura pesquisa, é por que autores como Renato Mendonça se distanciavam dessas correntes principais do pensamento linguístico da época.
} 
de preconceito e de análise simplista, as quais têm sido reputadas à IELPB por trabalhos ligados a tradições da Linguística brasileira contemporânea, devem ser consideradas noções historicamente marcadas, que, por certo, não fariam sentido dentro do estilo de pensamento escolhido por Silva Neto.

Por fim, notamos também que o diálogo entre Linguística e História se mostra bastante profícuo para o desenvolvimento de ambas as disciplinas, uma vez que a coesão entre os conhecimentos desenvolvidos nos diferentes campos pode levar ao fortalecimento de determinadas ideias e práticas. Aliás, esse diálogo não ficou circunscrito à tradição que possibilitou a emergência da IELPB, mas também tem sido bastante frequente nas tradições da Linguística contemporânea. A própria visão crítica em relação às propostas de Silva Neto (1963) para o tratamento do contato entre línguas pode ser vista como um reflexo desse diálogo, uma vez que também novas perspectivas historiográficas de interpretação do Brasil surgiram, salientando cada vez mais a participação de negros e indígenas na formação do país. É também por isso que, no âmbito dos estudos linguísticos, cresce cada vez mais o número de trabalhos que, nas áreas de Sociolinguística e História Social da Língua, procuram lançar novas luzes sobre a problemática do contato.

\section{Referências}

ALONSO, M. C. Multidimensionalidad, Complejidad y Dinamismo em la Historiografía Lingüística y en su definicíon del concepto de Tradicíon. Todas as Letras: revista de Língua e Literatura, São Paulo v. 14, n. 1, p. 71-86, 2012.

BASTOS, E. R. As Criaturas de Prometeu. Gilberto Freyre e a formação da sociedade brasileira. São Paulo: Global, 2006. p. 59-79.

COELHO, O. F. Serafim da Silva Neto (1917-1960) e a Filologia Brasileira: Um Ensaio Historiográfico sobre o Papel da Liderança na Articulação de um Paradigma em Ciência da Linguagem. 1998. 184f. Dissertação (Mestrado em Semiótica e Linguística Geral) - Faculdade de Filosofia, Letras e Ciências Humanas, Universidade de São Paulo, São Paulo, 1998.

COSTA, W. P. A Independência na Historiografia Brasileira. In: JANCSÓ, I. (Org.). Independência do Brasil: História e Historiografia. São Paulo: Hucitec/FAPESP, 2006, v.1, 2006. p. 53-117.

ELIA, S. E. O Problema da Língua Brasileira. 2. ed. Rio de Janeiro: Instituto Nacional do Livro, Ministério da Educação e Cultura, 1961.

FLECK, L. Gênese e Desenvolvimento de um fato científico. Belo Horizonte: Fabrefactum, 2010 .

KOERNER, E. F. K. Questões que persistem em Historiografia Linguística. Revista da ANPOLL, n. 2, p. 45-70, 1996. 
LOBO, T. Variantes nacionais do português: sobre a questão da definição do português do Brasil. Revista Internacional de Língua Portuguesa, n. 12, p. 9-16, 1994.

LUCCHESI, D. A diferenciação da língua portuguesa no Brasil e o contato entre línguas. Estudos de Linguística Galega, v. 4, p. 45-65, 2012.

MATTOS E SILVA, R. V. Ensaios para uma sócio-história do português brasileiro. São Paulo: Parábola, 2004.

MENDONÇA, R. A Influência Africana no Português do Brasil. 2.ed. São Paulo: Companhia Editora Nacional, 1935.

RAIMUNDO, J. O elemento afro-negro da Língua Portuguesa. Rio de Janeiro: Renascença Editora, 1933.

SILVA, W. S. Linguística Histórica no Brasil (1950-1990): estudo historiográfico das continuidades e descontinuidades no tratamento da variação e da mudança linguística do português brasileiro. 2016. 244f. Dissertação (Mestrado em Linguística) - Faculdade de Filosofia, Letras e Ciências Humanas, Universidade de São Paulo, São Paulo, 2016.

SILVA NETO, S. Introdução ao estudo da língua portuguesa no Brasil. 2.ed. Rio de Janeiro: Instituto Nacional do Livro, Ministério da Educação e da Cultura, 1963 [1950].

SWIGGERS, P. Les premières grammaires des vernaculaires gallo-romans face à la tradition latine: stragégies d'adaptation et de transformation. In: ROSIER, I. L'Heritage des Grammairiens Latins de L'Antiquité Aux Lumières. Actes du Colloque de Chantillty. Paris: Diffusion Éditions Peeters, 1988. p. 259-269.

. Modelos, Métodos y Problemas en la historiografía de la linguística.

Nuevas A portaciones a la historiografía linguística. Actas del IV Congresso Internacional de la SEHL. La Laguna (Tenerife), 22 al 25 de octubre de 2003. p. 113-146, 2004.

TARALLO, F. Sobre a alegada origen crioula do portugués brasileiro: mudanças sintáticas aleatórias. In: ROBERTS, I.; KATO, M. (Org.). Português Brasileiro: uma viagem diacrónica (uma homenagem a Fernando Tarallo). Campinas: Editora da Unicamp, 1993. VARnhagen, F. A. História geral do Brazil. Tomo Primeiro. Rio de Janeiro / Madrid V. de Dominguez, 1854. Disponível em: https://books.google.com.br/ books?id=MWoCAAAAYAAJ\&dq. Acesso em: 14 fev. 2017.

VELLINHO, M. A valorização do português na obra de Gilberto Freyre. In: Gilberto Freyre: sua Ciência, sua Filosofia, sua arte. Rio de Janeiro: Livraria José Olympio Editora, 1962.

Submetido em: $28 / 02 / 2017$

Aceito em: 04/07/2017 